\title{
Determining Factors for the Protectiveness of the Passive Film of FeCrN Stainless Steel Formed in Sulfuric Acid Solutions
}

\author{
Heon-Young $\mathrm{Ha}^{1,+}$ and Tae-Ho Lee ${ }^{1}$ \\ ${ }^{1}$ Advanced Metallic Materials Division, Korea Institute of Materials Science, \\ 797 Changwondaero, Seongsangu, Changwon, Gyeongnam, 642-831, South Korea \\ (Received July 1, 2013; Revised July 15, 2013; Accepted July 16, 2013)
}

\begin{abstract}
In $\mathrm{NaCl}$ solutions acidified with $\mathrm{H}_{2} \mathrm{SO}_{4}, \mathrm{Fe} 20 \mathrm{Cr} 1.1 \mathrm{~N}$ alloy showed enhanced pitting corrosion resistance than $\mathrm{Fe} 20 \mathrm{Cr}$ alloy. An XPS analysis revealed that the passive film of Fe20Cr1.1N alloy contained higher cationfraction of $\mathrm{Cr}$ than that of $\mathrm{Fe} 20 \mathrm{Cr}$ alloy, and nitrogen was incorporated into the film. In addition, it was found that the passive film of Fe20Cr1.1N alloy was thinner and had higher oxygen vacancy density than that of $\mathrm{Fe} 20 \mathrm{Cr}$ alloy. Based on these observations, it was concluded that the chemical composition was the determining factor for the protectiveness of the passive film of $\mathrm{Fe} 20 \mathrm{Cr}$ based alloy in dilute $\mathrm{H}_{2} \mathrm{SO}_{4}$ solution.
\end{abstract}

Keywords : stainless steel, nitrogen, sulfuric acid solution, passive film, Mott-Schottky, XPS

\section{Introduction}

It is widely agreed that the nitrogen as an alloying element enhances the pitting corrosion resistance of stainless steels, and the mechanism for the positive effect of nitrogen has been extensively investigated. ${ }^{1-9)}$ The dissolved nitrogen in stainless steel is reported to change the physical, chemical and electronic properties of the passive film, and many attempts have been made to correlate the changed properties with the passive film protectiveness. ${ }^{1,3,7,9-12)} \mathrm{A}$ consensus exists in the fact that the alloyed nitrogen changes the chemical composition and chemical structure of the passive film, which includes the increase in the cation fraction of chromium and nitrogen enrichment on the film-metal interface or its incorporation into the film. ${ }^{1,3,7,9-12)}$ The nitrogen effect of increasing the $\mathrm{Cr}$ content in the passive film formed on the nitrided stainless surface was reported by Willenbruch, ${ }^{13)}$ and the same phenomenon was observed in the passive film of $\mathrm{Fe} 20 \mathrm{Cr} 1.1 \mathrm{~N}$ alloy formed in a borate-phosphate buffer solution. ${ }^{11)}$ In addition, Olefjord" ${ }^{9)}$ provided the evidence of nitrogen-enrichment on the film-metal interface during a passivation of Fe20Cr20Ni6Mo (0.011, $0.19) \mathrm{N}$ alloys in an acidified chloride solution. Vanini ${ }^{10)}$ also reported the nitrogen-enrichment on the film-metal interface of Fe17Cr13Ni0.15N alloy, and Olsson ${ }^{14)}$ observed that phenomenon on the passive film of 2205 duplex stainless steelcontaining $0.2 \mathrm{wt} \%$ of nitrogen. As for the physical properties of the passive film, Olefjord ${ }^{9)}$ reported that the passive film thickness was not affected by nitrogen alloying in the Fe20Cr20Ni6Mo $(0.011,0.19) \mathrm{N}$ which was formed in the 0.1 $\mathrm{M} \mathrm{HCl}+0.4 \mathrm{M} \mathrm{NaCl}$ solution although the pitting corrosion resistance was increased by nitrogen addition. However, $\mathrm{Fu}^{15)}$ observed the increased thickness in the passive film of Fe19Cr19Mn2Mo0.96N alloy formed in $0.5 \mathrm{M} \mathrm{H}_{2} \mathrm{SO}_{4}+0.5$ $\mathrm{M} \mathrm{NaCl}$ solution. Besides the physico-chemical properties, electronic properties of the passive film were frequently investigated to evaluate the protectiveness of the film. ${ }^{11,16,17)}$ The relationship between the decrease in the defect density (that is, oxygen vacancy concentration) and the enhancement of the pitting corrosion resistance was observed in Fe21Cr13Ni5Mn2Mo2.47N alloy ${ }^{16)}$ and nitrogen-bearing 316 type stainless steel ${ }^{17)}$. Additionally, increase in the $2^{\text {nd }}$ donor density (that is, $\mathrm{Cr}^{6+}$ concentration) in the passive film was reported to be responsible for the stable passivity of nitrogen-bearing Fe20Cr alloy. ${ }^{11)}$ As listed above, the effect of nitrogen on the passive film properties appears in various aspects, and it is needed to find out which is the most important factor determining the passive film protectiveness of nitrogen-bearing stainless steel. Therefore, in this paper, the various properties of the passive films of $\mathrm{Fe} 20 \mathrm{Cr}$ and $\mathrm{Fe} 20 \mathrm{Cr} 1.1 \mathrm{~N}$ alloys formed in $\mathrm{H}_{2} \mathrm{SO}_{4}$ solution were investigated in terms of physical, chemical, and electronic structure, and the determining factor in the passive film protectiveness was proposed.

\footnotetext{
${ }^{\dagger}$ Corresponding author: hyha2007@kims.re.kr
} 


\section{Experimental}

\subsection{Materials and electrodes}

Investigated alloys were $\mathrm{Fe} 20 \mathrm{Cr}$ ( $\mathrm{Fe}-19.82 \mathrm{Cr}$ in wt\%) and Fe20Cr1.1N (Fe-20.64-1.07N in wt\%) alloys. Fe20Cr alloy was produced using a vacuum arc melting furnace. The sample was homogenized at $1200{ }^{\circ} \mathrm{C}$ for 100 minutes and hot rolled into plates of $3 \mathrm{~mm}$ thick. The hot rolled plate was solution annealed at $1050{ }^{\circ} \mathrm{C}$ and water quenched. Fe20Cr1.1N alloy was produced using a pressurized induction melting furnace under $\mathrm{N}_{2}$ partial pressure of 15 bar. After homogenization at $1250{ }^{\circ} \mathrm{C}$ for 2 hours, the ingot was hot rolled into a plate of $4 \mathrm{~mm}$ thick, and the plates were solution annealed at 1200 ${ }^{\circ} \mathrm{C}$ for 2 hours followed by water quenching. Fe20Cr1.1N alloy was confirmed to have a single austenite phase with a supersaturated nitrogen, and no precipitation was observed. For the electrochemical tests, the samples were mounted in an epoxy resin and mechanically ground to \#2000 using a SiC paper. For the XPS analysis, the samples were polished to $1 \mu \mathrm{m}$ using a diamond suspension. The exposed area for the electrochemical test was controlled to be $0.13 \mathrm{~cm}^{2}$ using electroplating tape.

\subsection{Electrochemical tests}

Electrochemical tests were carried out using a three-electrode cell, and a saturated calomel reference electrode (SCE) and a Pt plate for a counter electrode were used.
The electrochemical signal was monitored using a Reference 600 (GAMRY) potentiostat.

Pitting corrosion resistance of the alloys was evaluated using a potentiodynamic polarization test in the $0.2 \mathrm{M}$ chloride solutions with $0-0.05 \mathrm{M} \mathrm{H}_{2} \mathrm{SO}_{4}$ at a scan rate of $3 \mathrm{mV} \mathrm{s}^{-1}$. In order to reduce severe active dissolution during the polarization test in highly acidic solution (e.g., $0.2 \mathrm{M} \mathrm{NaCl}+0.05 \mathrm{M} \mathrm{H}_{2} \mathrm{SO}_{4}$ solution), the relatively fast potential sweep rate was chosen. Then, the protectiveness of the passive film was investigated in various angles. An XPS analysis was carried out to examine the film thickness and chemical structure of passive films of $\mathrm{Fe} 20 \mathrm{Cr}$ and $\mathrm{Fe} 20 \mathrm{Cr} 1.1 \mathrm{~N}$ alloys, which were grown in a deaerated $0.005 \mathrm{M} \mathrm{H}_{2} \mathrm{SO}_{4}$ solution by applying $0.3 \mathrm{~V}_{\mathrm{SCE}}$ for 4 hours. XPS measurement was performed using an ESCALab 250 spectrometer with an Al $\mathrm{k} \alpha$ anode X-ray source $(150 \mathrm{~W}$, $15 \mathrm{kV}, \mathrm{hv}=1486.6 \mathrm{eV}$ ). The nitrogen effect on the passive film thickness examined by the XPS was verified again by galvanostatic reduction test. In a deaerated $0.0005 \mathrm{M}$ $\mathrm{H}_{2} \mathrm{SO}_{4}$ solution, the passive films were potentiostatically formed at $-0.2 \mathrm{~V}_{\mathrm{SCE}}$ and $0.3 \mathrm{~V}_{\mathrm{SCE}}$ for 30 minutes, and then the films were reduced by applying constant cathodic current density of $-10 \mu \mathrm{Acm}^{-2}$. From the consumed charge during the cathodic reduction of the oxide film, the passive film thickness was calculated. ${ }^{18-20)}$ Lastly, donor density $\left(N_{D}\right)$ of the passive film was obtained from Mott-Schottky analysis. The two alloys were passivated in a deaerated

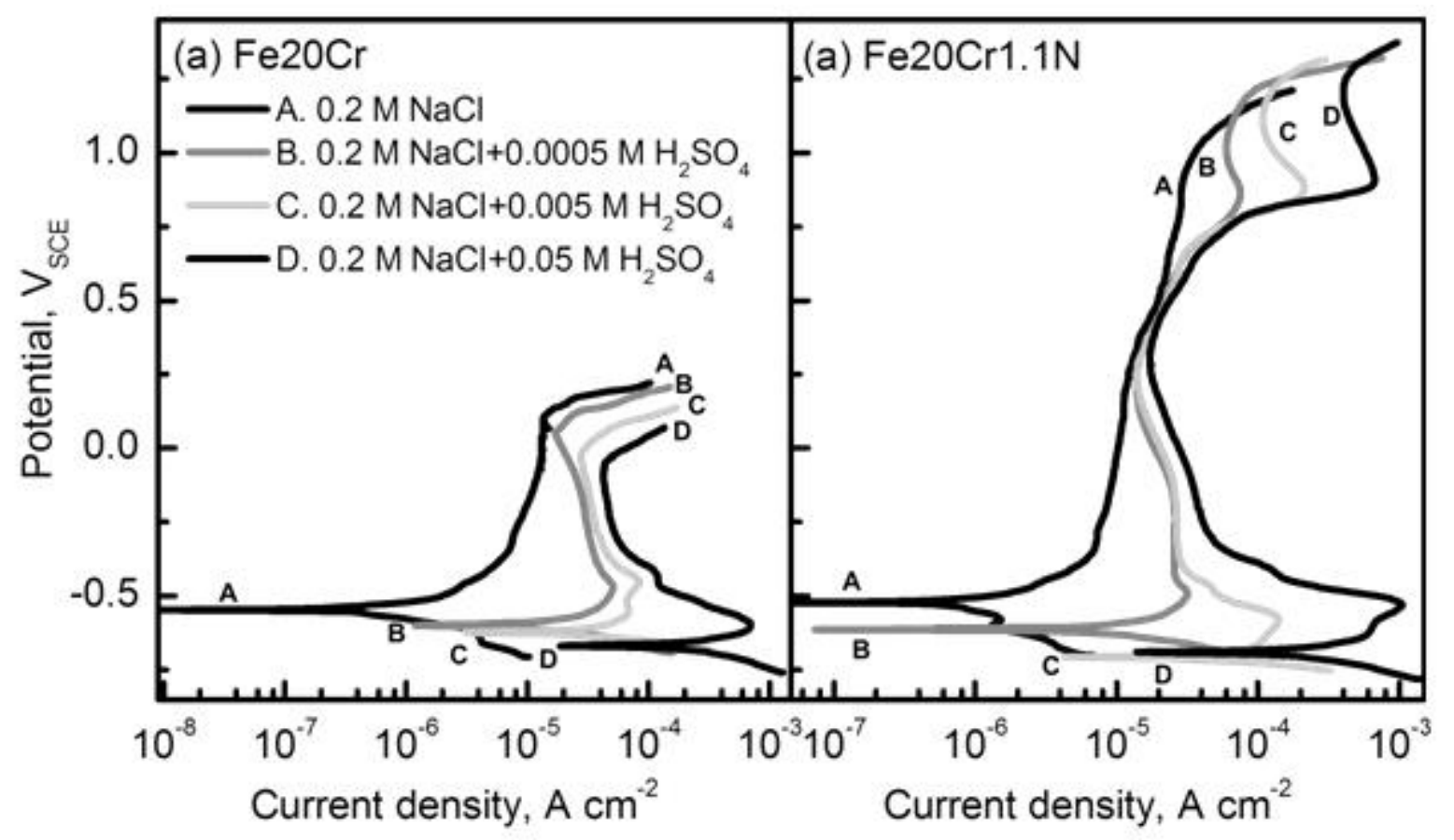

Fig. 1. Polarization curves of $\mathrm{Fe} 20 \mathrm{Cr}$ and $\mathrm{Fe} 20 \mathrm{Cr} 1.1 \mathrm{~N}$ alloys measured in deaerated $0.2 \mathrm{M} \mathrm{NaCl}$ solution with various concentrations of $\mathrm{H}_{2} \mathrm{SO}_{4}\left(20{ }^{\circ} \mathrm{C}\right)$ at a potential sweep rate of $3 \mathrm{mV} \mathrm{s}$. 
$0.1 \mathrm{M} \mathrm{H}_{2} \mathrm{SO}_{4}$ solution by applying $0.38 \mathrm{~V}_{\mathrm{SCE}}$ for 4 hours, and then the capacitance was measured by sweeping the applied potential in the negative direction from the film formation potential to $-0.46 \mathrm{~V}_{\mathrm{SCE}}$, while simultaneously imposing a small amplitude sinusoidal voltage perturbation of $10 \mathrm{mV}$ (peak-to-peak) at a frequency of $1000 \mathrm{~Hz}$. Before each electrochemical test, the working electrode was cathodically reduced at $-1.0 \mathrm{~V}_{\mathrm{SCE}}$ for 300 seconds to reduce an air-formed oxide. ${ }^{20-21)}$ Test solutions were deaerated by $\mathrm{N}_{2}$ purging and solution temperature was maintained at $20^{\circ} \mathrm{C}$. The polarization test, the galvanostatic reduction test and the Mott-Schottky analysis were performed at least 3 times, and good reproducibility was confirmed.

\section{Results and Discussion}

Fig. 1 shows polarization curves of the two alloys measured in deaerated $0.2 \mathrm{M} \mathrm{NaCl}$ solutions with various concentrations of $\mathrm{H}_{2} \mathrm{SO}_{4}$. In all solutions, pitting corrosion did not occur in Fe20Cr1.1N alloy while it took place in $\mathrm{Fe} 20 \mathrm{Cr}$ alloy, which confirmed the higher resistance against the pitting corrosion of nitrogen-bearing alloy. ${ }^{1,37}$ As $\mathrm{pH}$ decreased, that is $\mathrm{H}_{2} \mathrm{SO}_{4}$ concentration increased, a critical dissolution current density level increased and a corrosion potential level lowered in both alloys. Additionally, the pitting potential level of $\mathrm{Fe} 20 \mathrm{Cr}$ alloy decreased as the solution $\mathrm{pH}$ decreased (Fig. 1(a)). However, it was noted that the lowest passive current density of Fe20Cr1.1N alloy measured at approximately $0.3 \mathrm{~V}_{\mathrm{SCE}}$ was not significantly affected by the solution $\mathrm{pH}$.

The $\mathrm{pH}$ levels of the simple $0.2 \mathrm{M} \mathrm{NaCl}$ solution without $\mathrm{H}_{2} \mathrm{SO}_{4}$ and $0.2 \mathrm{M} \mathrm{NaCl}$ solution with $0.0005 \mathrm{M} \mathrm{H}_{2} \mathrm{SO}_{4}$ were 6.13 and 3.01, respectively. In these neutral and mild acid solutions, Fe20Cr and Fe20Cr1.1N alloys were passivated below their corrosion potential level, and hence the two alloys did not show the active-passive transition behavior. Meanwhile, in the strong acid solutions with a lower $\mathrm{pH}$ level than $2.5(0.2 \mathrm{M} \mathrm{NaCl}$ solution containing $0.005-0.05 \mathrm{M}$ $\mathrm{H}_{2} \mathrm{SO}_{4}$ ), the alloys clearly exhibited the active-passive transition as concretely discussed in the reference. ${ }^{21)}$ Defining the active and passive state of $\mathrm{Fe} 20 \mathrm{Cr}$ and $\mathrm{Fe} 20 \mathrm{Cr} 1.1 \mathrm{~N}$ alloy is important to determine the passivation potential for the subsequent experiments.

Fig. 1 clearly presents that the solutionized nitrogen is beneficial to the enhancement of the resistance to pitting corrosion of Fe20Cr-based alloy, and this result was observed in the acidified chloride solution with $\mathrm{H}_{2} \mathrm{SO}_{4}$ regardless of the solution $\mathrm{pH}$. In order to understand the reason for the promoted pitting corrosion resistance of Fe20Cr1.1N alloy, the characteristics of the passive film was closely investigated. Firstly, a thickness and a chem- ical structure of the passive film were investigated by an XPS analysis. The film was formed in deaerated 0.005 $\mathrm{M} \mathrm{H}_{2} \mathrm{SO}_{4}$ solution (pH 2.07) by applying a constant anodic potential of $0.3 \mathrm{~V}_{\mathrm{SCE}}$ for 4 hours, at which the lowest passive current density appeared. Fig. 2 shows the chemical composition depth profiles of the passive films of the alloys. The passive films of Fe20Cr and Fe20Cr1.1N alloys formed in a dilute $\mathrm{H}_{2} \mathrm{SO}_{4}$ solution were mainly composed of $\mathrm{Cr}, \mathrm{Fe}$ and $\mathrm{O}$. In both alloys, Fe content at the film surface was as low as 4 at $\%$, and it gradually increased to approximately 80 at $\%$. In addition, $\mathrm{Cr}$ content in the passive film was higher than that in the matrix, and its maximum value was approximately 30 at $\%$, which was shown at approximately $0.5 \mathrm{~nm}$ point from the film surface. Appreciable amount of nitrogen was detected in the passive film of Fe20Cr1.1N alloy, whose maximum value reached up to $5.44 \mathrm{at} \%$ at the film-metal interface. It was worth mentioning that the passive film of Fe20Cr1.1N alloy had higher $\mathrm{Cr}$ cation fraction $([\mathrm{Cr}] /[\mathrm{Fe}+\mathrm{Cr}])$ than that of $\mathrm{Fe} 20 \mathrm{Cr}$ alloy (Fig. 2(c)). At the film surface, the $\mathrm{Cr}$ fraction value

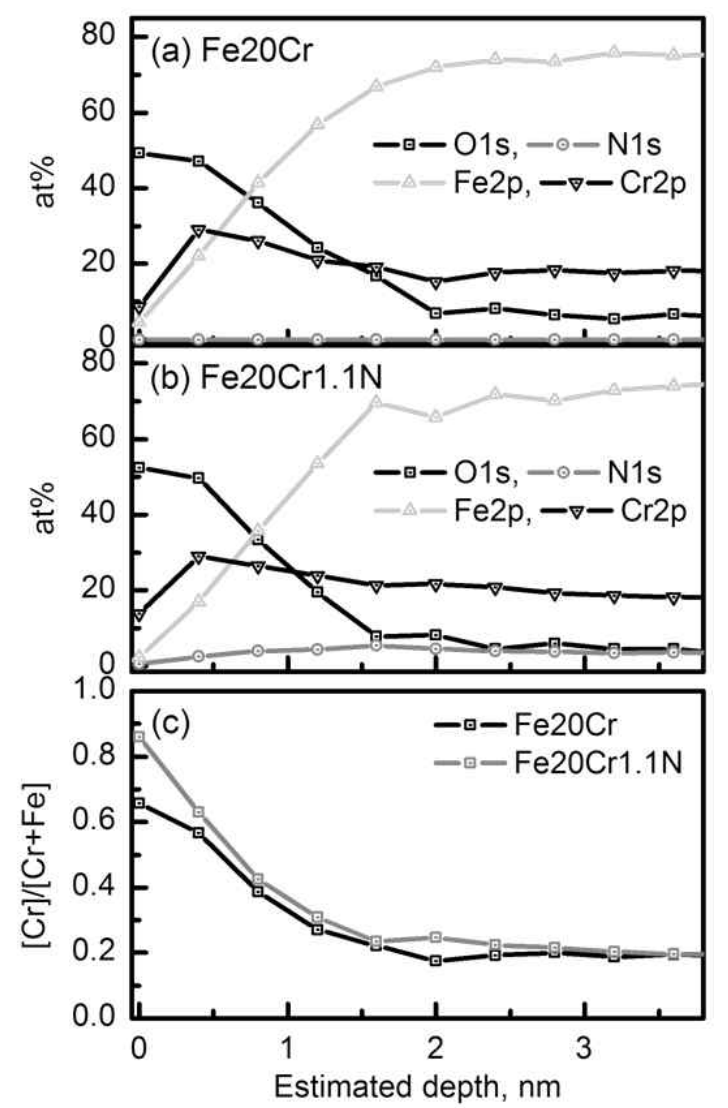

Fig. 2. Chemical composition depth profiles of the passivated surface of (a) Fe20Cr and (b) Fe20Cr1.1N alloys. (c) Depth profiles of the cation fraction of $\mathrm{Cr}([\mathrm{Cr}] /[\mathrm{Fe}+\mathrm{Cr}])$. The passive films were potentiostatically grown in deaerated $0.005 \mathrm{M} \mathrm{H}_{2} \mathrm{SO}_{4}$ solution (20 ${ }^{\circ} \mathrm{C}$ ) by applying constant potential of $0.3 \mathrm{~V}_{\mathrm{SCE}}$ for 4 hours. 
reached as high as 0.87 for $\mathrm{Fe} 20 \mathrm{Cr} 1.1 \mathrm{~N}$ alloy and 0.66 for $\mathrm{Fe} 20 \mathrm{Cr}$, respectively. The high $\mathrm{Cr}$ fraction over 0.5 at the film surface demonstrates that the passive film surface is mainly composed of $\mathrm{Cr}_{2} \mathrm{O}_{3}$, due to the higher solubility of $\mathrm{Fe}$ than $\mathrm{Cr}$ in $\mathrm{H}_{2} \mathrm{SO}_{4}$ solution. ${ }^{21,22)}$ The composition depth profiles of $\mathrm{O}$ and $\mathrm{Cr}$ shown in Fig. 2 also provide the information for the thickness of the passive film. The film-metal interface of $\mathrm{Fe} 20 \mathrm{Cr}$ alloy was located at approximately $2.0 \mathrm{~nm}$ from the surface, while that of Fe20Cr $1.1 \mathrm{~N}$ alloy was at approximately $1.6 \mathrm{~nm}$. The estimated film thickness based on Fig. 2 was further supported by the binding energy spectra of $\mathrm{O}_{1 \mathrm{~s}}$ (Fig. 3(a) and 3(b)) and $\mathrm{Cr}_{2 \mathrm{p}}$ (Fig. 3(c) and 3(d)). Fig. 3(a) and 3(b) shows two distinguishable peaks located at $530.4 \mathrm{eV}$ and 532.0 $\mathrm{eV}$, which correspond to the binding energy of $\mathrm{O}^{2-}$ (oxide) and $\mathrm{OH}^{-}$(hydroxide), ${ }^{9,14,23)}$ respectively. The $\mathrm{OH}^{-}$peak at
$532.0 \mathrm{eV}$ appeared only at the film surface. Fig. 3(a) and 3(b) show that the binding energy intensity of $\mathrm{O}_{1 \mathrm{~s}}$ more rapidly decreases in $\mathrm{Fe} 20 \mathrm{Cr} 1.1 \mathrm{~N}$ alloy than that of $\mathrm{Fe} 20 \mathrm{Cr}$ alloy with increasing in the sputtered depth. After the $4^{\text {th }}$ sputtering cycle (1.6 nm from the surface) of the passivated surface of Fe20Cr1.1N, $\mathrm{O}^{2-}$ peak at $530.4 \mathrm{eV}$ almost diminishes, while that for $\mathrm{Fe} 20 \mathrm{Cr}$ alloy is still distinguishable. The binding energy spectra of $\mathrm{Cr}_{2 \mathrm{p}}$ also support this observation. Fig. 3(c) and 3(d) show two peaks at 574.2 $\mathrm{eV}$ and $576.4 \mathrm{eV}$ which correspond to $\mathrm{Cr}^{0}$ (metal) and $\mathrm{Cr}^{3+}$ (oxide), respectively. ${ }^{23,24)}$ As sputtering proceeded, the $\mathrm{Cr}^{3+}$ (oxide) peak decreased and $\mathrm{Cr}^{0}$ (metal) peak increased. Comparing of Fig. 3(c) with 3(d), the retarded decrease in the intensity of the peak at $576.4 \mathrm{eV}\left(\mathrm{Cr}^{3+}\right.$ (oxide)) is observed in the passivated surface of $\mathrm{Fe} 20 \mathrm{Cr}$ alloy. From the $\mathrm{O}_{1 \mathrm{~s}}$ and $\mathrm{Cr}_{2 \mathrm{p}}$ binding energy spectra, it is con-
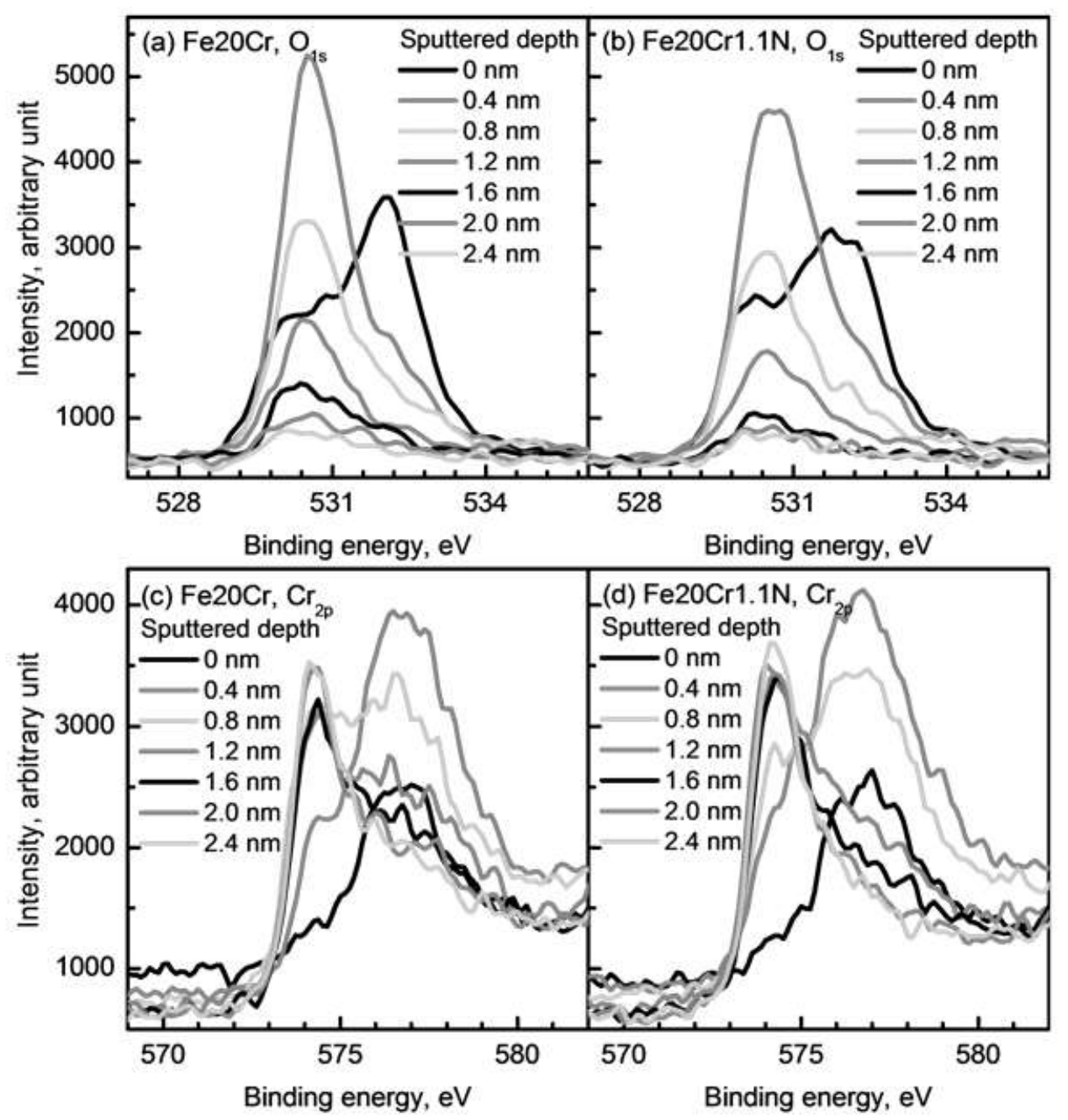

Fig. 3. Binding energy spectra of (a) $\mathrm{O}_{1 \mathrm{~s}}$ and (c) $\mathrm{Cr}_{2 \mathrm{p}}$ in the passivated $\mathrm{Fe} 20 \mathrm{Cr}$ alloy, and those of (b) $\mathrm{O}_{1 \mathrm{~s}}$ and (c) $\mathrm{Cr}_{2 \mathrm{p}}$ in the passivated $\mathrm{Fe} 20 \mathrm{Cr} 1.1 \mathrm{~N}$ alloy. The passive films were potentiostatically grown in deaerated $0.005 \mathrm{M} \mathrm{H}_{2} \mathrm{SO}_{4}$ solution $\left(20{ }^{\circ} \mathrm{C}\right)$ by applying constant potential of $0.3 \mathrm{~V}_{\mathrm{SCE}}$ for 4 hours. 
firmed that the film-metal interface of $\mathrm{Fe} 20 \mathrm{Cr}$ was located at approximately $2.0 \mathrm{~nm}$ from the surface and that for Fe20Cr1.1N was estimated to be $1.6 \mathrm{~nm}$.

As for the nitrogen-bearing alloy, the evidences of the nitrogen incorporation into the passive film and the nitrogen enrichment on the film-metal interface are clearly found in Fig. 4. Fig. 4(a) and 4(b) show the binding energy spectra of $\mathrm{N}_{1 \mathrm{~s}}$ at the film surface and matrix of $\mathrm{Fe} 20 \mathrm{Cr}$ and $\mathrm{Fe} 20 \mathrm{Cr} 1.1 \mathrm{~N}$ alloy, respectively. While no discriminable peak was observed in the binding energy spectra of the passivated surface on $\mathrm{Fe} 20 \mathrm{Cr}$ alloy without nitrogen, the distinctive $\mathrm{N}_{\mathrm{ls}}$ peak appeared in the passive film and the matrix of Fe20Cr1.1N alloy. The binding energy spectra of $\mathrm{N}_{\mathrm{ls}}$ were divided into two peaks located at $369.9 \mathrm{eV}$ and $397.7 \mathrm{eV}$. The $369.9 \mathrm{eV}$ is known as the binding energy of $\mathrm{Cr}-\mathrm{N}$ bonding, ${ }^{3,9,11,13,25)}$ and $397.7 \mathrm{eV}$ isreported to correspond to the binding energy levels of $\mathrm{Cr}-\mathrm{N}$ bonding ${ }^{3,10,13)}$ or $\mathrm{Cr}_{2} \mathrm{~N}$ nitrides. ${ }^{925)}$ As described in Fig. 2 and 3, the film thickness of Fe20Cr1.1N alloy was approximately $1.6 \mathrm{~nm}$, and Fig. 4(b) presents that the $\mathrm{N}_{1 \mathrm{~s}}$ peak with the highest intensity appears at the $1.6 \mathrm{~nm}$ depth point from the surface. Fig. 4(c) clearly shows that the incorporation of nitrogen into the film and the nitrogen-enrichment at the film-metal interface as well. In summary, the XPS analyses on the passive films of the alloys formed in dilute $\mathrm{H}_{2} \mathrm{SO}_{4}$ solution showed that both chromium and nitrogen concentrations increased in the passive film because of nitrogen alloying in the $\mathrm{Fe} 20 \mathrm{Cr}$ alloy matrix, and thinner passive film was formed on the nitrogen-bearing $\mathrm{Fe} 20 \mathrm{Cr}$ alloy.

The thinner passive film formation on Fe20Cr1.1N alloy than that of $\mathrm{Fe} 20 \mathrm{Cr}$ alloy was confirmed again by an electrochemical test. Galvanostatic reduction test was conducted on the passive films of the alloys, which were formed in $0.0005 \mathrm{M} \mathrm{H}_{2} \mathrm{SO}_{4}$ solution ( $\mathrm{pH} 3.04$ ) by applying constant passivation potential. Fig. 5(a) shows polarization curves measured in the $\mathrm{H}_{2} \mathrm{SO}_{4}$ solution at a scan rate of $3 \mathrm{mV} \mathrm{s}^{-1}$. In acid solutions above the $\mathrm{pH}$ level of approximately 3 , both alloys were passivated below their corrosion potential levels. ${ }^{21)}$ For this reason, $-0.2 \mathrm{~V}_{\mathrm{SCE}}$ and 0.3 $\mathrm{V}_{\mathrm{SCE}}$ were chosen as passivation potentials based on Fig. 5(a), and the passive films were potentiostatically grown at the determined potential levels for 30 minutes. Then, the films were galvanostatically reduced by applying a constant cathodic current density of $-10 \mu \mathrm{A} \mathrm{cm} \mathrm{cm}^{-2}$. Fig. 5(b) and 5(c) show the potential transition profiles against time conducted on the passive films formed at $-0.2 \mathrm{~V}_{\mathrm{SCE}}$ and $0.3 \mathrm{~V}_{\mathrm{SCE}}$, respectively. By applying the cathodic current density, the passive oxide films are reduced via the following reaction; $(\mathrm{Fe}, \mathrm{Cr})_{2} \mathrm{O}_{3}+6 \mathrm{H}^{+}+2 \mathrm{e}^{-} \rightarrow 2(\mathrm{Fe}, \mathrm{Cr})^{2+}$ $+3 \mathrm{H}_{2} \mathrm{O}{ }^{18)}$ and consequently the potential measured on the passivated metal surface decreases until reaching the stable potentiallevel. When the potential reaches the stable potential, the passive oxide layer can be considered to be fully reduced. The important result obtained from this test is the fact that the passive film of nitrogen-bearing alloy could be fully reduced with consuming less cathodic charge than that of $\mathrm{Fe} 20 \mathrm{Cr}$ alloy without nitrogen. From the consumed charge during the reduction, which was directly converted from the current applying time, the thickness of the passive film could be calculated. ${ }^{18,19)}$ Assuming the reduction efficiency was $100 \%$ because the test solution was mild acid solution with a $\mathrm{pH} 3.04,{ }^{26,27)}$ the passive film thickness was calculated using materials constants (passive film molecular weight $\left(\mathrm{M}_{(\mathrm{Fe}, \mathrm{Cr}) 2 \mathrm{O} 3}=155.84\right.$ $\mathrm{g} \mathrm{mol}^{-1}$, and passive film density $\left(\rho \gamma_{-(\mathrm{Fe}, \mathrm{Cr}) 2 \mathrm{O} 3}\right)=5.23 \mathrm{~g}$ $\mathrm{cm}^{-3}$ ). The calculated passive film thickness is displayed in Fig. 5(d). The film of Fe20Cr alloy formed at $-0.2 \mathrm{~V}_{\mathrm{SCE}}$ had a thickness of $0.67 \mathrm{~nm}$ and that formed at $0.3 \mathrm{~V}_{\mathrm{SCE}}$
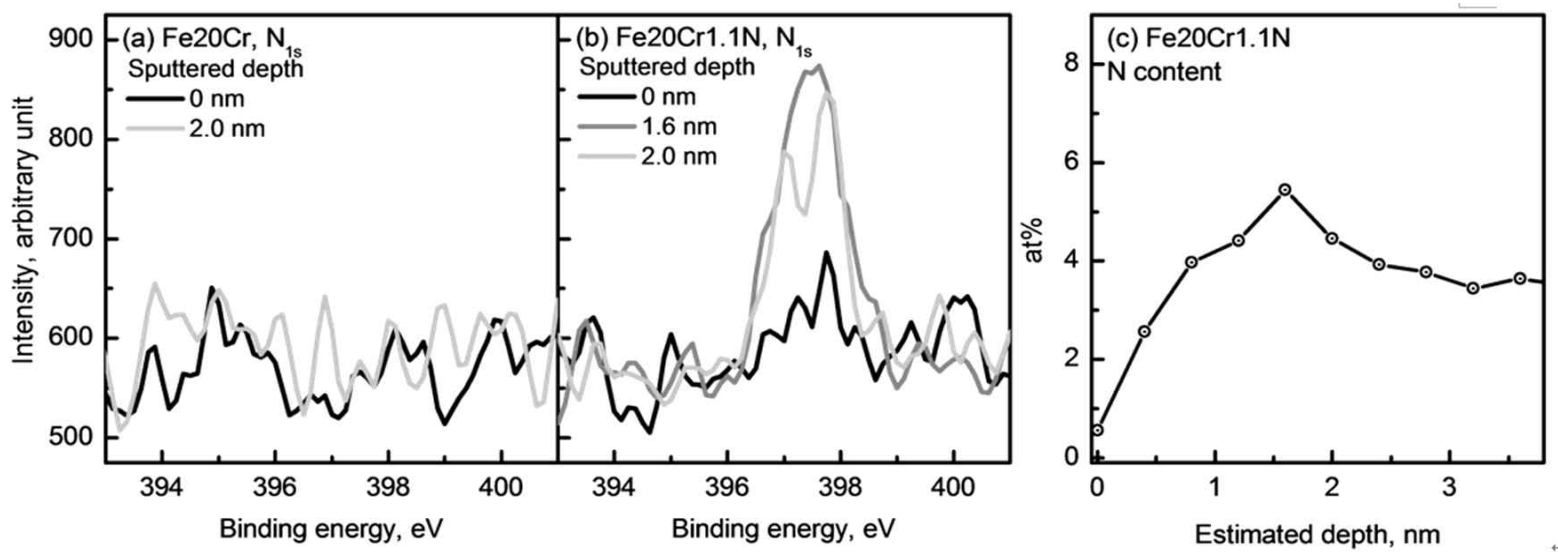

Fig. 4. Binding energy spectra of $\mathrm{N}_{1 \mathrm{~s}}$ in the passivated surface of (a) Fe20Cr and (b) Fe20Cr1.1N alloys. (c) Chemical composition depth profile of $\mathrm{N}$ in the passivated surface of Fe20Cr1.1N alloy. The passive films were potentiostatically grown in deaerated 0.005 $\mathrm{M} \mathrm{H}_{2} \mathrm{SO}_{4}$ solution $\left(20{ }^{\circ} \mathrm{C}\right)$ by applying constant potential of $0.3 \mathrm{~V}_{\mathrm{SCE}}$ for 4 hours. 

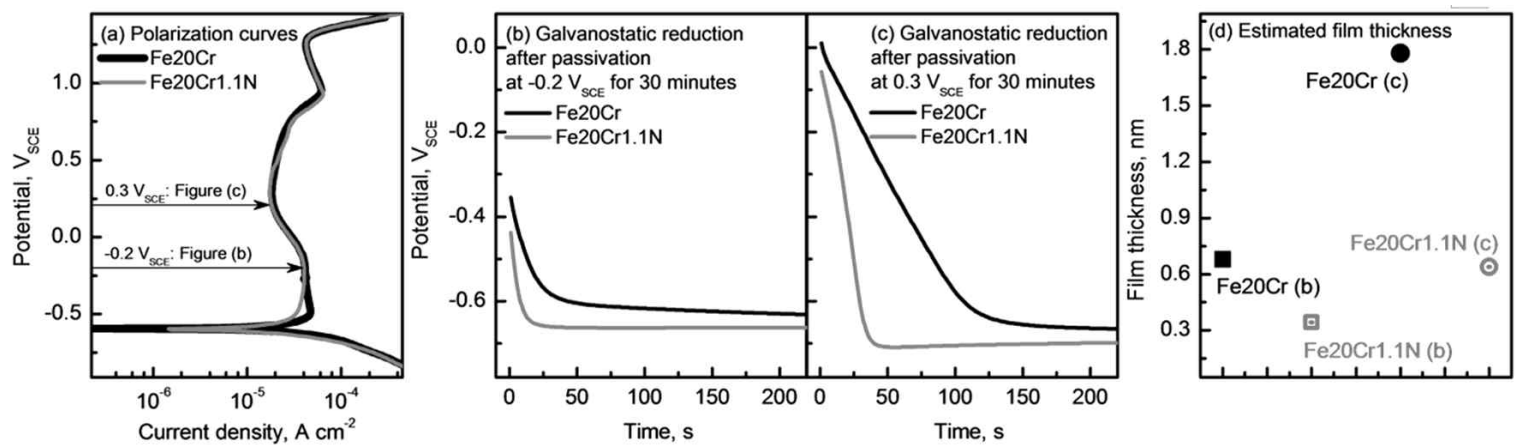

Fig. 5. (a) Polarization curves of $\mathrm{Fe} 20 \mathrm{Cr}$ and $\mathrm{Fe} 20 \mathrm{Cr} 1.1 \mathrm{~N}$ alloys measured in deaerated $0.0005 \mathrm{M} \mathrm{H}_{2} \mathrm{SO}_{4}$ solution $\left(20{ }^{\circ} \mathrm{C}\right)$ at a potential sweep rate of $3 \mathrm{mV} \mathrm{s}^{-1}$. Potential transition curve during the galvanostatic test by applying constant cathodic current density of -10 $\mu \mathrm{A} \mathrm{cm}{ }^{-2}$ of the alloys after passivation (b) at $-0.2 \mathrm{~V}_{\mathrm{SCE}}$ for 30 minutes and (c) at $0.3 \mathrm{~V}_{\mathrm{SCE}}$ for 30 minutes. (d) Film thickness of the alloys calculated from the galvanostatic test results.
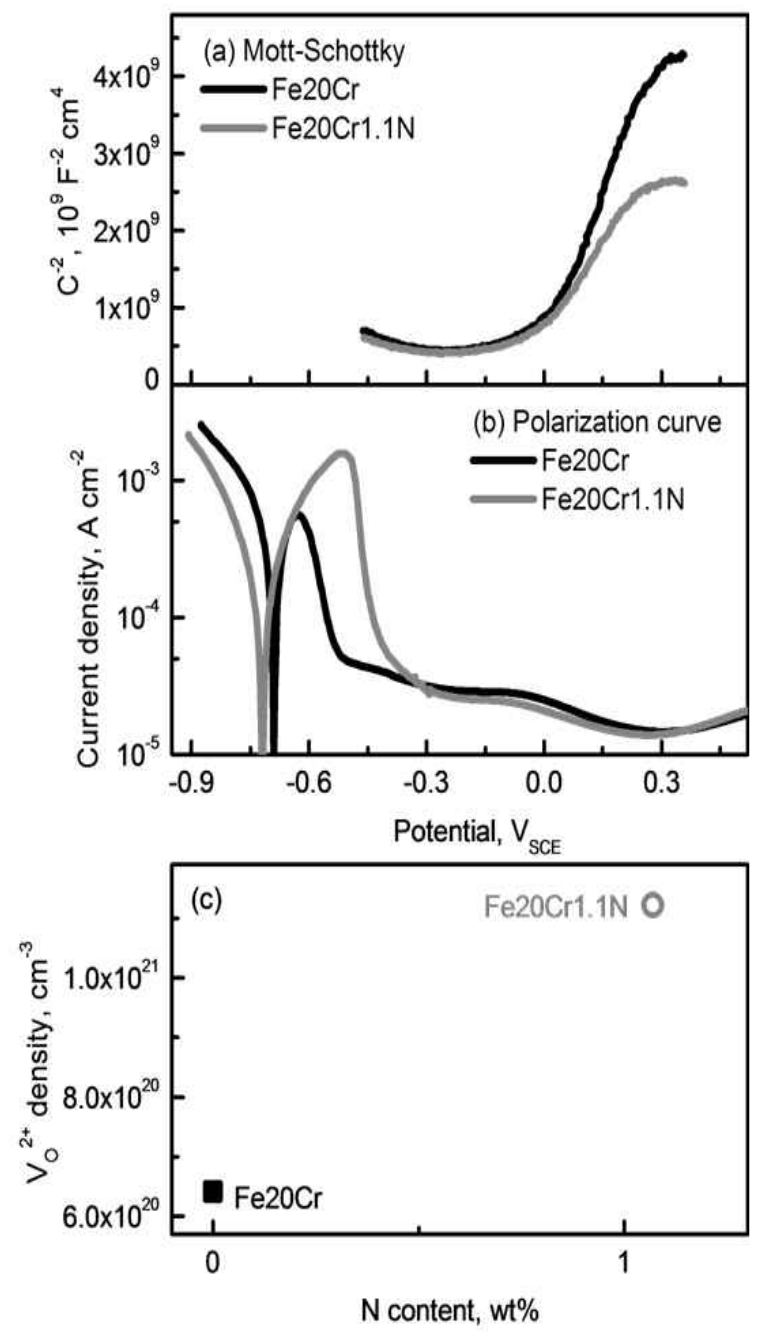

Fig. 6. (a) Mott-Schottky plots of Fe20Cr and Fe20Cr1.1N alloys measured in deaerated $0.1 \mathrm{M} \mathrm{H}_{2} \mathrm{SO}_{4}$ solution $\left(20{ }^{\circ} \mathrm{C}, 1000 \mathrm{~Hz}\right.$, $\pm 10 \mathrm{mV}$ ). (b) Polarization curves of the alloys measured the same solution at a potential sweep rate of $3 \mathrm{mV} \mathrm{s}^{-1}$. (c) Donor density of the alloys calculated from the Mott-Schottky analysis. was $1.77 \mathrm{~nm}$. In presence of nitrogen in the Fe20Cr matrix, the film thickness was calculated to be $0.34 \mathrm{~nm}$ at -0.2 $\mathrm{V}_{\mathrm{SCE}}$, and $0.63 \mathrm{~nm}$ at $0.3 \mathrm{~V}_{\mathrm{SCE}}$, respectively. In both cases, the passive film of Fe20Cr1.1N alloy appeared to be thinner than that of $\mathrm{Fe} 20 \mathrm{Cr}$ alloy, and this result supported the XPS results in Fig. 2.

As mentioned in the introduction section, the relationship between the semiconducting properties of the passive film and the pitting corrosion resistance has been widely investigated, and the point defect density in the passive film is reported to be responsible for the passive film protectiveness and hence the pitting corrosion resistance. ${ }^{11,16,17)}$ Thus, in an effort to understand this relationship, the passive films of $\mathrm{Fe} 20 \mathrm{Cr}$ and $\mathrm{Fe} 20 \mathrm{Cr} 1.1 \mathrm{~N}$ alloys were investigated using Mott-Schottky analysis.

A capacitance of a space charge layer in the passive film was measured in $0.1 \mathrm{M} \mathrm{H}_{2} \mathrm{SO}_{4}$ solution at $1000 \mathrm{~Hz}$, ${ }^{18,21)}$ and the Mott-Schottky curve was obtained as shown in Fig. 6(a). The polarization curves of the alloys measured at the same solution are displayed in Fig. 6(b), which present the stable passive potential regions of the alloys. The MottSchottky analysis was conducted on the passive film which was potentiostatically formed at $0.38 \mathrm{~V}_{\mathrm{SCE}}$ for 4 hours, and the capacitance value was measured in the passive potential range with descending the applying potential. Mott- Schottky plots of the alloys exhibit positive slopes $\left(d C_{S C} C^{-2} / d V\right)$ in the potential range of $0-0.3 \mathrm{~V}_{\mathrm{SCE}}$ (dashed line in Fig. 6(a)), which means the passive films of the two alloys have n-type semiconductivity. The n-type semiconductivity is due to the $\mathrm{Fe}_{2} \mathrm{O}_{3}$ component in the passive film. ${ }^{16-18,20,21)}$ In the n-type passive oxide film, the dominant and detectable donor species is an oxygen vacancy $\left(V_{O}{ }^{2+}\right),{ }^{16-18,20,21)}$ and the $N_{D}$ can be calculated from the Mott-Schottky plot, in accordance with the following relation between $C_{S C}$ and $E_{a p p}$ : 


$$
\frac{1}{C_{S C}^{2}}=\frac{1}{C_{\text {total }}^{2}}-\frac{1}{C_{H}^{2}}=\left(\frac{2}{\varepsilon \varepsilon_{o} e N_{D}}\right)\left(E_{a p p}-E_{F B}-\frac{k T}{e}\right)
$$

where $\varepsilon$ is the dielectric constant of the oxide $\left(15.6^{28), 29}\right)$, $\varepsilon_{0}$ is the vacuum permittivity $\left(8.854^{\prime} 10^{-14} \mathrm{~F} \mathrm{~cm}^{-1}\right), e$ is the electron charge, $E_{\text {app }}$ is the applied potential, and $k$ is the Boltzmann constant. The measured capacitance value, $C_{\text {total }}$, is obtained from the relation of $C_{\text {total }}=1 / \omega Z^{\prime \prime}$, where $\omega$ is the angular frequency $(1000 \mathrm{~Hz})$ and $Z^{\prime \prime}$ is the imaginary section of the specific impedance. $C_{\text {total }}$ is a series combination of a double layer capacitance (Helmholtz layer capacitance, $C_{H}$ ) and a space charge layer capacitance $\left(C_{S C}\right)$. Generally, the $C_{H}$ value is much higher than the $C_{S C}$ value thus, the measured capacitance $\left(C_{\text {total }}\right)$ can be regarded as $C_{S C}{ }^{20)}$

Based on Fig. 6(a), $N_{D}$ values of the alloys were calculated and displayed in Fig. 6(c). The $N_{D}$ value in the space charge layer of the passive films of $\mathrm{Fe} 20 \mathrm{Cr}$ was $6.41 \mathrm{x} 10^{20}$ $\mathrm{cm}^{-3}$, and that of $\mathrm{Fe} 20 \mathrm{Cr} 1.1 \mathrm{~N}$ alloy was $1.12 \times 10^{21} \mathrm{~cm}^{-3}$. The $V_{O}^{2+}$ is known to be the point defect in the passive film, and several reports have shown that lower $V_{O}^{2+}$ concentration in the passive films reflect higher protectiveness of the passive film ${ }^{16), 17), 20), 30), 31)}$. Thus, the analysis results from the Mott-Schottky plot cannot provide satisfactory explanation of the improved pitting corrosion resistance of Fe20Cr1.1N alloy.

So far, the series of analyses on the passive films of $\mathrm{Fe} 20 \mathrm{Cr}$ and $\mathrm{Fe} 20 \mathrm{Cr} 1.1 \mathrm{~N}$ alloys formed in dilute $\mathrm{H}_{2} \mathrm{SO}_{4}$ solution revealed various characteristics of the passive films. The XPS observation provided several important results as follows: (1) the frame of the passive films formed on the two alloys in dilute sulfuric acid solution were mixed $(\mathrm{Cr}, \mathrm{Fe})$-oxide. (2) The passive film with higher $\mathrm{Cr}$ fraction $([\mathrm{Cr}] /[\mathrm{Cr}+\mathrm{Fe}])$ was formed on the nitrogen-bearing $\mathrm{Fe} 20 \mathrm{Cr}$ alloy than that of $\mathrm{Fe} 20 \mathrm{Cr}$ alloy without nitrogen. (3) Nitrogen was incorporated into the passive film and enriched at the film-metal interface of Fe20Cr1.1N alloy. (4) The passive film on the Fe20Cr1.1N alloy was thinner than the $\mathrm{Fe} 20 \mathrm{Cr}$ alloy without nitrogen. Galvanostatic reduction test confirmed again that the thinner passive film was formed on the nitrogen-bearing alloy in the $\mathrm{H}_{2} \mathrm{SO}_{4}$ solution. In addition, Mott-Schottky analysis provided the results that more defective passive film containing higher $V_{O}^{2+}$ concentration was formed on the nitrogen- bearing alloy. The higher $\mathrm{Cr}$ content and incorporation of nitrogen in the passive film are known to contribute to the protectiveness of the passive film ${ }^{9-11), 13), 14), 32) .}$ However, the observed features that the film of $\mathrm{Fe} 20 \mathrm{Cr} 1.1 \mathrm{~N}$ alloy was thinner and more defective than that of $\mathrm{Fe} 20 \mathrm{Cr}$ alloy were reported to have adverse effect to strengthening the protective ability of the passive film ${ }^{9), 15)-17,30)}$. Thus, considering these results, the increased pitting corrosion resistance of Fe20Cr1.1N is considered primarily attributed to the chemical change of the passive film, that is the higher chromium and nitrogen content, and it can be concluded that the most important determining factor for strengthening the passive film protectiveness is the chemical structure than the film thickness and the defect density.

\section{Conclusions}

In this study, the resistance to the pitting corrosion resistance in dilute sulfuric acid of Fe20Cr and Fe20Cr1.1N alloy was evaluated by a potentiodynamic polarization test, and the characteristics of the passive films formed in the sulfuric acid solution were investigated through and an XPS and a galvanostatictest and Mott-Schottky analysis. From the investigation, the following results are obtained. 1. Nitrogen alloying was effective to enhance the resistance to pitting corrosion of $\mathrm{Fe} 20 \mathrm{Cr}$ based alloy in sulfuric acid solutions containing chloride ion. This result demonstrated that the higher protective passive film formed on Fe20Cr1.1N alloy in the sulfuric acid solution.

2. The XPS analysis revealed that the passive films of the two alloys formed in sulfuric acid solution were composed of $(\mathrm{Cr}, \mathrm{Fe})$-oxide, and the $\mathrm{Cr}$ cation fraction of $\mathrm{Fe} 20 \mathrm{Cr} 1.1 \mathrm{~N}$ alloy was higher than that of Fe20Cr alloy. In addition, nitrogen was incorporated with the passive film of Fe20Cr1.1N alloy, and the maximum content of nitrogen was found at the film-metal interface.

3. From the XPS analysis and the galvanostatic reduction result, it was found that the passive film formed on the nitrogen-bearing alloy was thinner than that on $\mathrm{Fe} 20 \mathrm{Cr}$ alloy without nitrogen.

4. Mott-Schottky analysis showed the passive film on Fe20Cr1.1N alloy had higher point defect density (oxygen vacancy density) than that of Fe20Cr alloy. It was concluded that the higher protectiveness of the passive film on $\mathrm{Fe} 20 \mathrm{Cr} 1.1 \mathrm{~N}$ alloy was mainly attributed to the higher chromium and nitrogen contents in the passive film than that of $\mathrm{Fe} 20 \mathrm{Cr}$ alloy. In addition, the protectiveness of the passive film was primarily determined by the chemical composition change in comparison to the film thickness and defect density.

\section{References}

1. P. R. Levey and A. van Bennekom, Corrosion, 51, 911 (1995).

2. M. Sumita, T. Hanawa and S. H. Teoh, Mat. Sci. Eng. C-Mater, 24, 753 (2004).

3. H. J. Grabke, ISIJ Int., 36, 777 (1996).

4. P. J. Uggowitzer, R. Magdowski and M. O. Speidel, ISIJ 
Int., 36, 901 (1996).

5. J. W. Simmons, Mat. Sci. Eng. A-Struct, 207, 159 (1996).

6. J. Menzel, W. Kirschner and G. Stein, ISIJ Int., 36, 893 (1996).

7. R. F. A. J.-Pettersson, Corros. Sci., 41, 1639 (1999).

8. K. H. Lo, C. H. Shek and J. K. L. Lai, Mat. Sci. Eng. $R, 65,39$ (2009).

9. I. Olefjord and L. Wegrelius, Corros. Sci., 38, 1203 (1996).

10. A. S. Vanini, J.-P.Audouard and P. Marcus, Corros. Sci., 36, 1825 (1994).

11. H. Ha, H. Jang and H. Kwon, Corros. Sci., 51, 48 (2009).

12. M. K. Lei and X. M. Zhu, J. Electrochem. Soc., 152, B291 (2005).

13. R. D. Willenbruch, C. R. Clayton, M. Oversluizen, D. Kim and Y. Lu, Corros. Sci., 31, 179 (1990).

14. C.-O. A. Olsson, Corros. Sci., 37, 467 (1995).

15. Y. Fu, X. Wu, E.-H. Han, W. Ke, K. Yang and Z. Jiang, Electrochim. Acta, 54, 4005 (2009).

16. M. Metikos-Hukovic, R. Babic, Z. Grubac, Z. Petrovic and N. Lajci, Corros. Sci., 53, 2176 (2011).

17. S. Ningshen, U. K. Mudali, V. K. Mittal and H. S. Khatak, Corros. Sci., 49, 481 (2007).

18. S. Ahn and H. Kwon, J. Electroanal. Chem., 579, 311 (2005).

19. K. N. Goswami and R. W. Staehle, Electrochim. Acta, 16, 1895 (1971).

20. H.-Y. Ha and H.-S. Kwon, J. Electrochem. Soc., 159, C416
(2012).

21. H.-Y. Ha, T.-H. Lee and S.-J. Kim, Electrochim. Acta, 80, 432 (2012).

22. T. Massoud, V. Maurice, L. H. Klein and P. Marcus, J. Electrochem. Soc., 160, C232 (2013).

23. H. Luo, X. G. Li, C. F. Dong and K. Xiao, Surf. Interface Anal., 45, 793 (2013).

24. A. Kocijan, C. Donik and M. Jenko, Corros. Sci., 49, 2083 (2007).

25. C. M. Abreu, M. J. Cristobal, P. Merino, X. R. Novoa, G. Pena and M. C. Perez, Electrochim. Acta, 53, 6000 (2008).

26. N. Sato, K. Kudo and T. Noda, Electrochim. Acta, 16, 1909 (1971).

27. N. Sato, K. Kudo and R. Nishimura, J. Electrochem. Soc., 123, 1419 (1976).

28. A. M. P. Simoes, M. F. S. Ferreira, B. Rondot and M. Da Cunha Belo, J. Electrochem. Soc., 137, 82 (1990).

29. E. Cho, H. Kwon and D. D Macdonald, Electrochim. Acta, 47, 1661 (2002).

30. S. Ahn, H. Kwon and D. D. Macdonald, J. Electrochem. Soc., 152, B482 (2005).

31. N. Li, Y. Li, S. Wang and F. Wang, Electrochim. Acta, 52, 760 (2006).

32. A. Shahryari, S. Omanovic and J. Z. Szpunar, Mat. Sci. Eng. C-Mater, 28, 94 (2008). 